\title{
Evacuation of a Tertiary Neonatal Centre: Lessons from the 2016 Kumamoto Earthquakes
}

\author{
Osuke Iwata $^{a}$ Akihiko Kawase $^{b}$ Masanori Iwaic Kazuko Wada ${ }^{d}$ \\ ${ }^{a}$ Centre for Developmental and Cognitive Neuroscience, Department of Paediatrics and Child Health, \\ Kurume University School of Medicine, Fukuoka, ${ }^{\mathrm{b}}$ Division of Neonatology, Kumamoto City Hospital, and \\ 'Department of Pediatrics, Kumamoto University School of Medicine, Kumamoto, and ${ }^{\mathrm{d}}$ Department of \\ Pediatrics, Osaka University School of Medicine, Osaka, Japan
}

\section{Keywords}

Natural disaster · Hospital evacuation · Transportation · Newborn infant

\begin{abstract}
Background: Newborn infants hospitalised in the neonatal intensive care unit (NICU) are vulnerable to natural disasters. However, publications on evacuation from NICUs are sparse. The 2016 Kumamoto Earthquakes caused serious damage to Kumamoto City Hospital and its level III regional core NICU. Local/neighbour NICU teams and the disaster-communication team of a neonatal academic society cooperated to evacuate 38 newborn infants from the ward. Objective: The aim of this paper was to highlight potential key factors to improve emergency NICU evacuation and coordination of hospital transportation following natural disasters. Methods: Background variables including clinical risk scores and timing/destination of transportation were compared between infants, who subsequently were transferred to destinations outside of Kumamoto Prefecture, and their peers. Results: All but 1 of the infants were successfully evacuated from their NICU within $8 \mathrm{~h}$. One very-low-birth-weight infant developed moderate hypothermia following transportation.
\end{abstract}

\begin{tabular}{ll}
\hline KARGER & $\begin{array}{l}\text { ( } 2017 \text { The Author(s) } \\
\text { Published by S. Karger AG, Basel }\end{array}$ \\
$\begin{array}{l}\text { E-Mail karger@karger.com } \\
\text { www.karger.com/neo }\end{array}$ & $\begin{array}{l}\text { Karger } \\
\text { NonCon article is licensed under the Creative Commons Attribution- } \\
\text { NC-ND) (http://www.karger.com/Services/OpenAcesessLicense) }\end{array}$ \\
& $\begin{array}{l}\text { Usage and distribution for commercial purposes as well as any dis- } \\
\text { tribution of modified material requires written permission. }\end{array}$
\end{tabular}

Fourteen infants were transferred to NICUs outside of Kumamoto Prefecture, which was associated with the diagnosis of congenital heart disease, dependence on respiratory support, higher risk scores, and longer elapsed time from the decision to departure. There was difficulty in arranging helicopter transportation because the coordination office of the Disaster Medical Assistance Team had requisitioned most air/ground ambulances and only helped arrange ground transportations for 13 low-risk infants. Transportation for all 10 high-risk infants (risk scores greater than or equal to the upper quartile) was arranged by local/neighbour NICUs. Conclusions: Although the overall evacuation process was satisfactory, potential risks of relying on the adult-based emergency transportation system were highlighted. A better system needs to be developed urgently to put appropriate priority on vulnerable infants.

@ 2017 The Author(s)
Published by S. Karger AG, Basel

\section{Introduction}

Japan is subject to frequent earthquakes, which have caused serious damage to hospitals [1-3]. Newborn infants hospitalised in the neonatal intensive care unit 
(NICU) are vulnerable to disasters [4, 5]. However, publications on evacuation from NICUs are sparse. Here we report our first-hand experience of a total evacuation of a level III NICU to highlight potential key factors to facilitate safe, swift, and efficient emergency hospital evacuation and transportation following natural disasters.

\section{Population and Methods}

Kumamoto Prefecture (online suppl. Fig.1; for all online suppl. material, see www.karger.com/doi/10.1159/000466681) has a population of 1,790,000 and annual births of 15,700. Kumamoto City Hospital had the largest (42 cots) of 3 NICUs within Kumamoto Prefecture, which hospitalised 65\% of extremely-low-birthweight infants and most infants requiring cardiac surgeries born within the prefecture in 2015. The main hospital building, which housed the NICU on the third floor, was erected in 1984 and had been recognised as being susceptible to earthquakes.

Information regarding the patients' clinical background and evacuation process was obtained from the data archive of the disaster-communication secretary of the Japan Society for Neonatal Health and Development (JSNHD). The risk for transportation was quantified for each infant using an originally developed composite score, which comprised a categorical rating for immaturity $(0-3)$, respiratory support (0-4), and vascular routes (0-3) during transportation (online suppl. Table 1). Variables were compared between infants who were transferred to destinations outside of Kumamoto Prefecture and their peers, using the Student $t$ test, $\chi^{2}$ test, Fisher exact test, or Spearman rank correlation coefficient. Values are shown as means \pm standard deviation unless otherwise specified.

\section{Results}

\section{Evacuation Process}

On April 14,1 2016, a magnitude 6.5 preshock struck Kumamoto Prefecture, but did not cause serious damage to hospital buildings or equipment (casters diagonally locked). NICU staff checked the route and priority of evacuation (i.e., from low-care to high-care).

A magnitude 7.0 mainshock occurred at 1:25 a.m. on April 16, causing extensive damage to Kumamoto City Hospital. Another strong aftershock at 1:45 a.m. prompted the decision to evacuate all patients within the hospital, including 38 infants in the NICU [Table 1; online suppl. Table 2]. Twenty nurses (including 10 early-nightshift nurses) and 3 neonatologists were available for the primary evacuation. Because the elevators were unavailable and the stairs within the building were damaged, infants were transferred from the third floor to an out- side parking area through an external emergency staircase. Although the weather was fine, the outside air temperature was $14^{\circ} \mathrm{C}$, rendering it difficult to keep infants warm without using incubators. Thus, the infants were transferred to a rehabilitation room on the ground floor, due to this difficulty. Self-inflating bags, oxygen cylinders, and infusion-pumps were available to continue medical care for 7 intubated infants, 9 infants on nasal oxygen/ventilatory support, and 14 infants who required continuous intravenous infusions. Many infants had to share a cylinder with peers because only 4 oxygen cylinders were available. At 2:30 a.m., the chief neonatologist began contacting neighbour NICUs and the disastercommunication secretary of JSNHD by mobile phone to arrange transportation of the patients. Parents were informed that their infants were safe but required hospital transportation using mobile/landline phones.

One level III NICU in Kurume $(75 \mathrm{~km}$ north of $\mathrm{Ku}$ mamoto) attempted to arrange helicopter transportation, which was soon requisitioned by the coordination office of the Disaster Medical Assistance Team (DMAT). The chief neonatologist of Kumamoto City Hospital then requested the DMAT coordination office to arrange helicopter transportation of sick infants. However, the DMAT coordination office only helped arrange ground transportation 5 times for 13 stable infants. Helicopter transportation (3 flights) was subsequently arranged after 7:00 a.m. independent of the DMAT coordination office.

At approximately 4:00 a.m., NICU teams in Kurume, Saga, and Kagoshima left for Kumamoto using their own neonatal ambulances. Another level III, 24-cot NICU at Kumamoto University Hospital was intact, which started transferring infants to its NICU using their own neonatal ambulance at 4:00 a.m. The number of intubated infants safely transported at a time was limited to $1-2$, who were subsequently grouped with other stable infants to travel on the same ambulance. Another neonatal ambulance owned by Kumamoto City Hospital left for Fukuoka at 5:30 a.m. to transfer 3 infants with congenital heart disease. Shortly before 7:00 a.m., the neonatal ambulances from Kurume, Saga, and Kagoshima reached Kumamoto City Hospital to transport 6 infants to their own hospitals. By 9:30 a.m., all but 1 infant, who was waiting for a long-distance helicopter flight to the hospital of its birth, had been successfully evacuated. Throughout evacuation, no adverse event was noted except for a very-lowbirth-weight infant, who developed hypothermia to $33^{\circ} \mathrm{C}$ following hospital transfer.

Neonatology 2017;112:92-96 DOI: $10.1159 / 000466681$ 
Table 1. Variables potentially affecting the decision of destination

\begin{tabular}{|c|c|c|c|c|}
\hline & \multirow[t]{2}{*}{ All infants } & \multicolumn{2}{|c|}{ Transprefectural transportation ${ }^{\mathrm{d}}$} & \multirow[t]{2}{*}{$p$} \\
\hline & & no & yes & \\
\hline Postnatal age, days & $60.3 \pm 76.8$ & $54.2 \pm 76.6$ & $70.6 \pm 78.8$ & $0.532^{\dagger}$ \\
\hline Corrected age, weeks & $42.0 \pm 10.8$ & $40.6 \pm 9.0$ & $44.4 \pm 13.4$ & $0.303^{\dagger}$ \\
\hline $\begin{array}{l}\text { Indication for hospitalisation } \\
\text { Low birth weight }(<2,500 \mathrm{~g}) \\
\text { Very low birth weight }(<1,500 \mathrm{~g}) \\
\text { Extremely low birth weight }(<1,000 \mathrm{~g}) \\
\text { Major/multiple congenital anomaly } \\
\text { CHD } \\
\text { Surgical disease excluding CHD } \\
\text { Indication other than above }\end{array}$ & $\begin{array}{r}26(68.4) \\
13(34.2) \\
6(15.8) \\
12(31.6) \\
8(21.1) \\
6(15.8) \\
4(10.6)\end{array}$ & $\begin{aligned} 17 & (70.8) \\
7 & (29.2) \\
4 & (16.7) \\
4 & (16.7) \\
1 & (4.2) \\
6 & (25.0) \\
4 & (16.6)\end{aligned}$ & $\begin{array}{l}9(64.3) \\
6(42.9) \\
2(14.3) \\
8(57.1) \\
7(50.0) \\
0(0.0) \\
0(0.0)\end{array}$ & $\begin{array}{l}0.679^{\dagger \dagger} \\
0.163^{\dagger \dagger} \\
0.847^{\dagger \dagger} \\
0.011^{\dagger \dagger} \\
0.001^{\dagger \dagger} \\
0.044^{\dagger \dagger} \\
\text { na }\end{array}$ \\
\hline $\begin{array}{l}\text { Respiratory support }{ }^{\mathrm{b}} \\
\text { Invasive } \\
\text { Invasive or noninvasive } \\
\text { Invasive, noninvasive, or oxygen }\end{array}$ & $\begin{array}{r}7(18.4) \\
14(36.8) \\
16(42.1)\end{array}$ & $\begin{array}{l}2(8.3) \\
4(16.7) \\
5(20.8)\end{array}$ & $\begin{array}{r}5(35.7) \\
10(71.4) \\
11(78.6)\end{array}$ & $\begin{array}{l}0.077^{\dagger \dagger} \\
0.001^{\dagger \dagger} \\
0.001^{\dagger \dagger}\end{array}$ \\
\hline $\begin{array}{l}\text { Vascular catheters }^{\mathrm{b}} \\
\text { Multiple vascular catheters } \\
\text { Any vascular catheter }\end{array}$ & $\begin{array}{c}1(2.6) \\
14(36.8)\end{array}$ & $\begin{array}{l}0(0.0) \\
7(29.2)\end{array}$ & $\begin{array}{l}1(7.1) \\
7(50.0)\end{array}$ & $\begin{array}{l}\text { na } \\
0.205^{\dagger \dagger}\end{array}$ \\
\hline $\begin{array}{l}\text { Risk score }^{\mathrm{b}} \\
\quad \text { Score } \\
\text { Scores } \geq 4 \text {, high risk } \\
\text { Time from decision to departure, } \mathrm{h}\end{array}$ & $\begin{aligned} 1 & \{1,4\} \\
10 & (26.3) \\
4.5 & \pm 1.8\end{aligned}$ & $\begin{aligned} & 1\{0.25,2\} \\
& 2(8.3) \\
3.8 & \pm 1.0\end{aligned}$ & $\begin{aligned} & 4\{1.75,4\} \\
& 8(57.1) \\
5.8 & \pm 2.1\end{aligned}$ & $\begin{array}{l}0.002^{\ddagger} \\
0.002^{\dagger \dagger} \\
<0.001^{\dagger}\end{array}$ \\
\hline $\begin{array}{l}\text { Means of transportation } \\
\text { Ambulance (universal) } \\
\text { Neonatal ambulance } \\
\text { Helicopter } \\
\text { Other (taxi/personal vehicle) }\end{array}$ & $\begin{aligned} 13 & (34.2) \\
20 & (52.6) \\
3 & (7.9) \\
2 & (5.3)\end{aligned}$ & $\begin{aligned} 11 & (45.8) \\
11 & (45.8) \\
0 & (0.0) \\
2 & (8.3)\end{aligned}$ & $\begin{array}{l}2(14.3) \\
9(64.3) \\
3(21.4) \\
0(0.0)\end{array}$ & $\begin{array}{l}0.077^{\dagger \dagger} \\
0.278^{\dagger \dagger} \\
\text { na } \\
\text { na }\end{array}$ \\
\hline $\begin{array}{l}\text { Type of destination hospital } \\
\text { Level II or III perinatal centre } \\
\text { Level III perinatal centre } \\
\text { Level III perinatal CHD centre }\end{array}$ & $\begin{array}{r}35(68.4) \\
23(36.8) \\
7(18.4)\end{array}$ & $\begin{array}{c}21(87.5) \\
10(41.7) \\
0(0.0)\end{array}$ & $\begin{array}{r}14(100) \\
13(92.9) \\
7(50.0)\end{array}$ & $\begin{array}{l}0.283^{\dagger \dagger} \\
0.002^{\dagger \dagger} \\
<0.001^{\dagger \dagger}\end{array}$ \\
\hline
\end{tabular}

Values are shown as means $\pm \mathrm{SD}, n(\%)$, or median $\{25 / 75$ percentiles $\} .{ }^{\dagger}$ Student $t$ test, $\chi^{2}$ test. ${ }^{\dagger \dagger}$ Fisher exact test. ${ }^{\ddagger}$ Spearman rank correlation coefficient. Statistical significance was assumed for $p$ values $<0.0025$ correcting for multiple comparisons (Bonferroni correction). ${ }^{\text {a }}$ Including respiratory failure $(n=2)$, jaundice $(n=1)$, and maternal diabetes $(n=1)$. ${ }^{\mathrm{b}}$ Risk scores for transportation comprised a categorical rating for corrected age, respiratory support, and blood access. See online supplemental Table 1 for the details of the score and its items. ${ }^{c}$ Hospitals that provide regular surgical treatments for infants with CHD. ${ }^{\mathrm{d}}$ Subgroups defined according to destinations, i.e., within or outside Kumamoto Prefecture. CHD, congenital heart disease.

\section{Variables Associated with the Coordination of}

\section{Transportation}

Thirty-eight infants (18 females and 20 males) of 33.4 \pm 4.8 weeks' gestation and $42.0 \pm 10.8$ weeks' corrected age travelled $49 \pm 61 \mathrm{~km}$ to their destinations. The risk score ranged between 0 and 6 . None of high-risk infants with top quartile scores $\geq 4$ was transferred by the ar- rangement of the DMAT coordination office (Fig. 1). Fourteen infants were transferred to destinations outside of Kumamoto Prefecture, which was associated with the diagnosis of congenital heart disease $(p=0.001)$, higher dependence on invasive/non-invasive respiratory support $(p=0.001)$, higher risk scores $(p=0.002)$, and longer elapsed time from the decision of evacuation to the ac- 


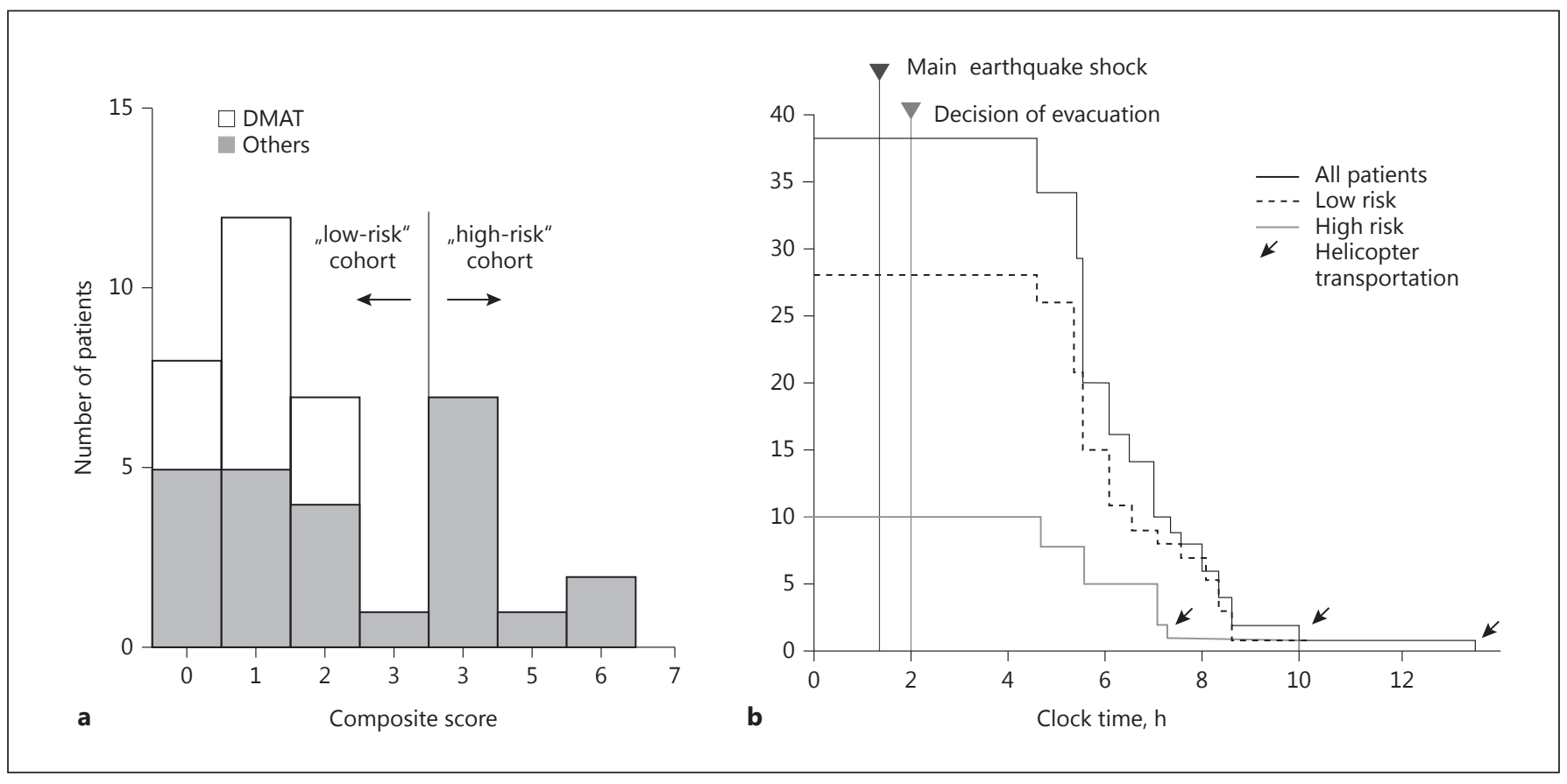

Fig. 1. Transportation risk and subsequent evacuation of 38 infants. a Histogram of the composite risk scores for the transportation of 38 infants. Open bars, infants transferred by the DMAT coordination office. Shaded-bars, infants transferred by the NICU network (i.e., independent of the DMAT coordination office). Note that transportation of infants requiring high-dependency care with the composite scores of equal to or greater than the upper quartile (indicated as "high-risk" quartile) were exclusively ar-

tual departure from Kumamoto City Hospital $(p<0.001)$. Referral to level III NICUs was more common for infants who were transported outside of Kumamoto Prefecture than their peers $(p=0.002)$.

\section{Discussion}

Despite failure in cooperation with the DMAT coordination office, the NICU team of Kumamoto City Hospital succeeded in evacuating the majority of patients within 8 h by closely cooperating with neighbouring NICU teams. The disaster communication team of JSNHD helped facilitate a network with remote NICUs using its online directory and a range of communication tools including internet phone, text messages, and social networking services. This directory was created after the 2011 Great East Japan Earthquake, when interhospital communication was disrupted because of the differential loss of communication tools in different regions [6].

Evacuation of Infants from a Tertiary

Neonatal Centre ranged by the NICU network. b Timing of evacuation from Kumamoto City Hospital plotted along the clock time on the $\mathrm{x}$-axis for "all patients," the "high-risk" subgroup, and their "low-risk" peers. The pace of evacuation was similar between the 2 subgroups, highlighting the difficulty in putting a priority on the transportation of high-risk infants. DMAT, Disaster Medical Assistance Team; NICU, neonatal intensive care unit.

Several conditions, which worked in favour of an expeditious evacuation, need to be taken into account. For example, nurses who had finished the early night shift were still around. There was no high-risk delivery during the evacuation. Physicians/nurses were able to use a range of communication tools. The number of casualties was relatively small, leading to the availability of ambulances for in-hospital patients. Ground transportation was possible despite the damage to the highways.

Newborn infants are susceptible to stressors, and can easily become hypothermic [5]. Prolonged manual ventilation may cause tube dislodgement/obstruction. Thus, for sick infants, the risk of long-distance transportation should be minimised using helicopters or neonatal ambulances. It was unfortunate that the DMAT coordination office did not offer helicopter transportation for infants. A potential danger in relying on the current triage system to assess the order of emergency transportation for NICU infants has been indicated. Janvier et al. [7] reported that physicians and students gave significantly

Neonatology 2017;112:92-96 95 
lower value of life to newborn infants compared to children/adults with similar risks of death and having impairments, when all patients needed immediate resuscitation. Cohen et al. [4] concluded that the current triage systems for adults are not applicable to neonates. Based on the experience during Hurricane Katrina, Klein et al. [8] emphasised the necessity for triage assessment tools for NICU infants.

In 2014 , only $67 \%$ of hospitals in Japan were earthquake resistant [9]. The reconstruction plan of Kumamoto City Hospital had been postponed because of budget constraints, whereas the 2 other earthquake-proof NICUs in Kumamoto were undamaged. A program to make hospitals earthquake-resistant must be accelerated in regions around the world affected by earthquakes.

\section{Conclusions}

This was the first experience of total evacuation of a tertiary NICU after an earthquake. Preparedness in disaster management is important even in regions where earthquakes are rare, as reports from hurricanes suggest $[8,10]$. Although the overall process of the evacuation was satisfactory, our failure in cooperation with the DMAT coordination office revealed covert but serious risks in relying on the adult-based coordination system of transportation. A better system needs to be developed urgently for vulnerable newborn infants. Meanwhile, for the evacuation of NICU, neonatologists should collaborate with the DMAT coordination office to put appropriate priority on NICU infants.

\section{Acknowledgements}

The authors thank Drs. Hiroshi Mitsubuchi, Masanori Tamura, Satoshi Kusuda, Masayuki Ochiai, Yuichi Kondo, Daijiro Takahashi, Tadashi Hisano, Toshimitsu Takayanagi, Mamoru Saikusa, Yoshinobu Maede, Eiji Hirakawa, and Shigeru Ohki, and the physicians and nurses in Kumamoto who are dedicated to secure the safety of vulnerable newborn infants.

\section{Disclosure Statement}

The authors have no conflicts of interest relevant to this article to disclose. The first draft of the manuscript was written by Dr. Iwata.

\section{Funding Source}

This work was performed without grant support; however, publication of this article was supported by the Japanese Ministry of Health, Labour, and Welfare (Maternal and Neonatal Transportation, 009-H28, general, medicine). Dr. Iwata is funded by The Japan Science and Technology Agency (H27-001, Special Research in Perinatal Medicine) and the Japan Society for the Promotion of Science, The Ministry of Education, Culture, Sports, Science, and Technology (Grant-in-Aid for Scientific Research C16K09005).

\section{References}

1 Nagamatsu S, Maekawa T, Ujike Y, Hashimoto $\mathrm{S}$, Fuke N: The earthquake and tsunami observations by Japanese physicians since the 11 March catastrophe. Crit Care 2011;15:167.

2 Tanaka H, Iwai A, Oda J, Kuwagata Y, Matsuoka T, Shimazu T, et al: Overview of evacuation and transport of patients following the 1995 Hanshin-Awaji earthquake. J Emerg Med 1998;16:439-444.

3 Tanaka K: The Kobe earthquake: the system response. A disaster report from Japan. Eur J Emerg Med 1996;3:263-269.

4 Cohen R, Murphy B, Ahern T, Hackel A: Regional disaster planning for neonatology. J Perinatol 2010;30:709-711.
-5 Perlman JM, Wyllie J, Kattwinkel J, Wyckoff MH, Aziz K, Guinsburg R, et al: Part 7: neonatal resuscitation: 2015 international consensus on cardiopulmonary resuscitation and emergency cardiovascular care science with treatment recommendations (reprint). Pediatrics 2015;136(suppl 2):S120-S166.

6 Iwata O, Oki T, Ishiki A, Shimanuki M, Fuchimukai T, Chosa T, et al: Infection surveillance after a natural disaster: lessons learnt from the Great East Japan Earthquake of 2011. Bull World Health Organ 2013;91:784789.
7 Janvier A, Leblanc I, Barrington KJ: Nobody likes premies: the relative value of patients' lives. J Perinatol 2008;28:821-826.

8 Klein KR, Pepe PE, Burkle FM Jr, Nagel NE, Swienton RE: Evolving need for alternative triage management in public health emergencies: a Hurricane Katrina case study. Disaster Med Public Health Prep 2008;2(suppl 1):S40S44.

9 Results of Surveys on the Status of Making Social Welfare Facility. Tokyo, Ministry of Health, Welfare and Labour, 2016.

10 Ginsberg HG: Sweating it out in a level III regional NICU: disaster preparation and lessons learned at the Ochsner Foundation Hospital. Pediatrics 2006;117:S375-S380. 